\title{
Consumption Home Bias and Exchange Rate Behavior*
}

\section{Dudley Cooke ${ }^{\dagger}$}

\section{Trinity College Dublin}

\section{November 2007}

\begin{abstract}
This paper studies the response of the nominal exchange rate to monetary shocks in an economy with consumption home bias (CHB) and sticky wages. The importance of accounting for the exchange rate with $\mathrm{CHB}$ are twofold. CHB is a consequence of the small open economy assumption when outputs are specialized and fluctuations in the relative price of traded goods generate deviations from purchasing power parity without violating the law of one price. The $\mathrm{CHB}$ mechanism allows monetary shocks to generate exchange rate dynamics. However, output is more sensitive to the parameter that governs expenditure switching when there is CHB. Limiting the output response to monetary shocks, whilst still generating exchange rate dynamics, places a stronger emphasis on expenditure shifting, compared to the situation in which deviations from purchasing power parity arise from failures in the law of one price.
\end{abstract}

JEL Classification: E58, F32, F41.

Keywords: Consumption Home Bias, Exchange Rate, Monetary Shocks, Consumption Substitutability.

*Thanks to Philip Lane, Neil Rankin, and seminar participants in Copenhagen, Leuven, and Warwick for comments and suggestions. Financial Support from the ESRC (\#R42200134107) is gratefully acknowledged.

$\dagger$ †epartment of Economics, Trinity College Dublin, College Green, Dublin 2, Ireland. Email: dcooke@tcd.ie; URL: http://www.tcd.ie/Economics/staff/dcooke; Tel: +353 (0)1 896 2049, Fax: +353 (0)1 6772503. 


\section{Introduction}

This paper studies the response of the nominal exchange rate to monetary shocks in a dynamic general equilibrium model of a small open economy with sticky wages. It focuses on the role played by consumption home bias (CHB). CHB is present in most small open economies, and because it allows for deviations from purchasing power parity, plays an important role in the transmission of shocks. ${ }^{1} \quad$ Because the law of one price holds, accounting for the exchange rate when there is $\mathrm{CHB}$ also forms a benchmark case. Monetary shocks and sticky wages produce exchange rate fluctuations when there is $\mathrm{CHB}$. However, because $\mathrm{CHB}$ generates a strong expenditure switching effect, monetary shocks produce larger changes in output compared to the case in which short run deviations in the law of one price break purchasing power parity. As a result, a stronger reliance is placed on the expenditure shifting effects of monetary shocks.

CHB alters the reaction of the nominal exchange rate to monetary shocks through two distinct channels. One channel works through the net foreign asset (NFA) position of the economy whilst the second depends on a liquidity effect. When neither of these channels operate, the domestic currency depreciates in proportion to a permanent unanticipated monetary shock, both on impact, and in the long run. A monetary expansion causes long run asset accumulation if (i), the elasticity of substitution between domestic and foreign goods is relatively high, or (ii), the intertemporal elasticity of substitution in consumption is relatively low. ${ }^{2}$ Changes in the NFA position are reflected in the response of the exchange rate to shocks, and in either case, the plausible outcome is a dampening of the exchange rate's response to monetary shocks versus the flex-wage case. Finally, monetary shocks produce genuine exchange rate dynamics if money demand is not unit interest elastic. With $\mathrm{CHB}$, monetary shocks lower the real interest rate, and this requires a change in the nominal interest rate to clear the money market. Arbitrage then produces an initial over or under reaction in the short run exchange rate, the extent of which reduces as the economy becomes more open.

Even when the law of one price holds, monetary shocks can produce sizable changes in the exchange rate. However, absent mechanisms which introduce additional dynamics into the

\footnotetext{
${ }^{1}$ Empirically, the majority of consumption consistes of locally produced goods (Kollmann, 2006).

${ }^{2}$ The first of these channels is due to expenditure switching. Exchange rate depreciations improve the terms of trade, which induce domestic agents to import less and export more. The second occurs because of expenditure shifting. A lower real interest rate induces domestic agents to reduce current consumption in favor of future consumption. $\mathrm{CHB}$ is necessary for the second effect to operate.
} 
economy, the NFA and liquidity effect channels need to both be present for monetary shocks to generate strong exchange rate movements alongside output reactions that are not themselves in excess of the change in the exchange rate. The substitutability of consumption over time, between goods, and with money balances all play a key role in this. ${ }^{3}$ Intuitively, we might expect the short run reaction of the exchange rate to be larger than that of output. However, for values of the elasticity of substitution between domestic and foreign goods only slightly greater than one expenditure switching causes output to react by far more than the exchange rate. If we instead focus solely on the liquidity effect, the initial reaction of the exchange rate is larger than the shock, but always proportional to output. To generate a large liquidity effect we need the interest elasticity of money demand to be high, but that implies a very low consumption elasticity, which is inconsistent with empirical estimates. However, if we instead suppose changes in NFAs are generated mainly through expenditure shifting, the output reaction is reduced, and a monetary expansion still leads to an initial trade surplus. In this case, we can also raise the consumption elasticity of money demand without affecting the interest elasticity, and exchange rate fluctuations remain large relative to 'fundamentals'.

This paper focuses on $\mathrm{CHB}$ as a source of deviations from purchasing power parity, motivated by the idea that there is a greater degree of home bias in big countries than small countries. ${ }^{4}$ However, one might equally assume deviations from purchasing power parity arise from the breakdown of the law of one price for traded goods, due to pricing to market (PTM), or movements in the relative price of traded to non traded goods. ${ }^{5}$ Obstfeld and Rogoff's (2000) well-known objections to the PTM assumption are based on evidence that there is a negative correlation between the exchange rate and the terms of trade. They suggest that deviations from the law of one price arise because non traded goods prices are incorporated into the CPI for goods that appear tradable. However, at short and medium run horizons, the relative price of non traded goods contribute very little to fluctuations in the real exchange rate (Engel, 1999). Whilst

\footnotetext{
${ }^{3}$ At least quantitatively, the liquidity effect alters the process of asset accumulation very little, and likewise, asset accumulation alters the initial reaction of the exchange rate only slightly. However, the former is important for the behavior of the exchange rate, and the latter for output.

${ }^{4}$ Warnock (2003) also provides a characterization of the exchange rate when there is CHB using the two (large) country framework of Obstfeld and Rogoff (1995). This paper generalizes that analysis along a number of dimensions. Most importantly, the intertemporal elasticity of substitution in consumption, which plays a key role in the analysis, differs from one. Second, the extent of market competition does not determine the strength of expenditure switching, and finally, CHB depends on the degree of openness and the relative size of the economy, as in Faia and Monacelli (2006).

${ }^{5}$ For a recent analysis of the law of one price, see Tesar and Gorodnichenko (2007).
} 
fluctuations in the relative price of traded goods has received less attention, it is arguably as relevant for the majority of small open economies in generating movements in the real exchange rate. The PTM versus non traded goods discussion is ongoing. Quantitative analyses assuming PTM can be found in Kollmann (2001), Chari et al. (2002), Monacelli (2004), Bergin (2003, 2006), and Jung (2007). ${ }^{6}$ The introduction of a non traded good has been analyzed by Lane (2001) and Hau (2002). Recently, Dotsey and Duarte (2007) have stressed the relevance of non traded goods over the PTM approach in matching exchange rate behavior along with other business cycle statistics.

This paper also focuses largely on the initial reaction of the exchange rate to monetary shocks. Evidence from vector auto regressions (VARs), such as those used by Eichenbaum and Evans (1995) and Kim and Roubini (2000), are unsupportive of the idea that there is a short run over reaction of the exchange rate. They identify two puzzles. A perverse result in which the exchange rate depreciates when there is a monetary contraction; and a "delayed overshooting" result, where the peak response of the exchange rate is some months after the shock. Faust and Rogers (2003), however, who also use a VAR analysis, relax some of the zero contemporaneous restrictions used to identify these open economy VARs, and find evidence of overshooting, and in the 'right' direction, but that this may be a result of non-monetary factors. Event studies, which rely on far weaker identifying assumptions, and restrict their attention to the impact reaction of the policy shock, are more supportive. Zettelmeyer (2004), for example, identifies monetary policy shocks by the reaction of three month market interest rates to policy announcements that were not themselves endogenous to economic news on the same day. Exchange rate depreciations are attributed to reverse causality, and a percentage contractionary shock appreciates the exchange rate by $2-3$ percent on impact.

\section{Model Economy}

The world is comprised of two economies. The total population of the domestic economy is indexed on a unit interval, and the population of the foreign economy is $\omega$. Other than this, the economies are identical.

\subsection{Preferences, Technology, and Market Clearing Conditions in the Domestic Economy}

\footnotetext{
${ }^{6}$ This literature owes much to Betts and Devereux's (2000) original PTM extension of Obstfeld and Rogoff (1995). Empirically, and for the US, Gopinath and Rigobon (2007) find local currency pricing for imports and producer currency pricing for exports.
} 
Domestic firms produce a specialized output using differentiated labor types. Domestic households consume domestic and foreign outputs, supply labor, hold nominal money balances, and have access to a single period foreign currency bond. They also set the wage at which they are willing to supply labor one period in advance. Household $j$ 's preferences and firm $j$ 's technology take the following form.

$$
\begin{aligned}
U_{0} & =\sum_{t=0}^{\infty} \beta^{t}\left[\frac{C_{t}^{1-\rho}}{1-\rho}+\frac{a}{1-\epsilon}\left(\frac{M_{t}}{P_{t}}\right)^{1-\epsilon}-\kappa l_{t}\right] \\
C_{t} & =\left((1-\nu)^{1 / \lambda} C_{h, t}^{(\lambda-1) / \lambda}+\nu^{1 / \lambda} C_{f, t}^{(\lambda-1) / \lambda}\right)^{\lambda /(\lambda-1)} ; \nu=(1-\gamma) \phi \\
y_{t} & =\left(\int_{0}^{1} l_{t}(j)^{(\sigma-1) / \sigma} d j\right)^{\sigma /(\sigma-1)} ; \sigma>1
\end{aligned}
$$

where $\nu$ measures the overall share of the foreign good in the domestic consumption basket, $\phi \in$ $[0,1]$ measures the extent of openness, and $\gamma \equiv 1 /(1+\omega)$ is the share of the domestic population in the world population. The parameter $\lambda$ is the elasticity of substitution in consumption between domestic and foreign outputs, and $\rho$ is the inverse of the intertemporal elasticity of substitution in consumption ( $\lambda>1$ and $\rho<1$ imply relatively strong substitution effects). Given this form of preferences, $\rho / \epsilon$ is the consumption elasticity of money demand, with $\epsilon$ capturing the inverse interest elasticity of money demand. This final distinction is important because, when $\rho=1, \epsilon$ determines the consumption and interest elasticity of money demand. ${ }^{7}$

The budget constraints and first order conditions are standard, and are relegated to the Appendix, along with the details of the small open economy approximation, and an analysis of the closed economy. To complete the model, I specify equilibrium in the money market by summing across the $j$ agents, and setting money demand equal to supply. Monetary policy is the sequence of $\mu_{t} \equiv M_{t} / M_{t-1}$ for $t=0, \ldots, \infty$. Equilibrium in the goods market occurs when GDP is equal to consumption of the domestically produced good in the domestic and foreign economies; $y_{t}=C_{h, t}+\omega C_{h, t}^{*}$. Labor market equilibrium, given preferences and technology, imposes that the nominal wage equal the GDP deflator in the individuals labor supply condition. Balanced trade occurs when nominal GDP equals total nominal consumption; $\Gamma_{t} \equiv y_{t} P_{h, t}-P_{t} C_{t}=0$. However, only the present value of trade surpluses need equal initial net indebtedness; $\left(1+i_{-1}\right) B_{-1}=$

\footnotetext{
${ }^{7}$ The Frisch elasticity of labor supply is assumed to be infinite mostly for analytical convenience, and can be justified by the indivisiblity of labor, as in Hansen (1985). Linearity eliminates much of the persistence that the model could generate. We also know from Kollmann (2001) and Chari et al. (2002) that separability in leisure is important for volatility, albeit when there is capital accumulation and PTM.
} 
$-\sum_{t=0}^{\infty} \Gamma_{t} /\left[\left(1+i_{0}\right) \ldots\left(1+i_{t-1}\right)\right]$, where $i_{t}$ is the domestic nominal interest rate. Lastly, the uncovered interest rate parity condition is $s_{t}\left(1+i_{t}\right)=s_{t+1}\left(1+i_{t}^{*}\right)$.

\subsection{Linearized Conditions}

To analyze the dynamic behavior of the model, I take a linear approximation around a zero inflation, zero trade balance steady-state, with a zero initial level of net foreign assets. In the analysis below I rely on the following conditions.

$$
\begin{aligned}
& \epsilon \widehat{M}_{t}-\epsilon \widehat{P}_{t}=\rho \widehat{C}_{t}-\widehat{i}_{t} \beta \\
& \widehat{\Omega}_{t}=\widehat{\Omega}_{t+1}-(1-\beta) \widehat{i}_{t}+\frac{\rho-1}{\rho}(1-\beta) \widehat{r}_{t} \\
& \widehat{s}_{t}=\widehat{s}_{t+1}-(1-\beta) \widehat{i}_{t} \\
& \widehat{P}_{t}=n \widehat{P}_{h, t}+(1-n) \widehat{P}_{f, t} \\
& 0=\sum_{t=0}^{\infty} \beta^{t} \widehat{\Gamma}_{t} \\
& \widehat{\Gamma}_{t}=(1-n)\left[\Theta \widehat{s}_{t}-\widehat{\Omega}_{t}+(1+n)(1-\lambda) \widehat{P}_{h, t}\right] \\
& \widehat{y}_{t}=(1-n) \Theta \widehat{s}_{t}+n \widehat{\Omega}_{t}+\left[n^{2}(\lambda-1)-\lambda\right] \widehat{P}_{h, t} \\
& \widehat{P}_{h, t}=\widehat{P}_{t}+\rho \widehat{C}_{t}
\end{aligned}
$$

where $\widehat{\Omega}_{t} \equiv \widehat{C}_{t}+\widehat{P}_{t}$ is nominal consumption, $n \equiv 1-\phi$, so that $n=1$ represents the closed economy, and $\Theta \equiv \lambda+n(\lambda-1)>0$. All variables with 'hats' represent deviations from their respective steady-state values, except $\widehat{\Gamma}_{t}$, which is the deviation from $\Omega$, since $\Gamma=0 .{ }^{8}$ Equation (1) is money demand, (2) the consumption Euler equation, (3) is UIP, (4) is the CPI, (5) is the intertemporal budget constraint (IBC) for the economy, (6) is the trade balance, (7) is the goods market clearing condition, and (8) is the aggregate supply relationship.

\subsection{Reduced Form Expressions for the Exchange Rate}

I consider what happens to the nominal exchange rate when there is an unanticipated permanent change in the level of the money supply, such that at date $t=0, \widehat{M}_{t}$ jumps from zero to $\widehat{M}$. Since agents are endowed with perfect foresight, markets clear in all periods after the shock, and

\footnotetext{
${ }^{8}$ The same is true for the intial level of net foreign assets. There, $a_{-1} \equiv \frac{\left(1+i_{-1}\right) B_{-1}}{\Omega}$, where $a_{-1}$ is assumed to be zero.
} 
so in period $t=1$, the economy reaches a new steady-state. Using these assumptions, I can derive reduced form expressions for the short and long run reaction of the nominal exchange rate.

Money demand and the consumption Euler equation together determine the closed economy aggregate demand relationship; $\widehat{i}_{0}=\frac{(1-\beta)(\epsilon-1)}{1+(1-\beta)(\epsilon-1)} \widehat{r}_{0}$, and because there are nominal rigidities, $\widehat{r}_{0} \neq 0 .{ }^{9}$ However, when $\epsilon=1, \widehat{i}_{0}=0$, so given the shock we are considering, the nominal interest rate must jump immediately to it's new steady state. When $\epsilon \neq 1$, the real side of the economy affects the nominal interest rate, leading to a possible liquidity effect from monetary policy. Equilibrium in financial markets requires the UIP condition to hold. Using the CPI, and definition of the real exchange rate, we can write a reduced form expression for the short run nominal exchange rate, rf-UIP.

$\widehat{s}_{0}=\widehat{s}+\underbrace{\frac{\varpi}{1-\varpi}}_{\text {as } \epsilon \neq 1} \widehat{P}_{h}$

where $\varpi \equiv n(1-\beta)(\epsilon-1) /[1+(1-\beta)(\epsilon-1)]<1$, and $\widehat{P}_{h}$ denotes the long-run change in the GDP deflator. Since $\widehat{P}_{h} \neq 0$, there are non-trivial exchange rate dynamics which rely on a link between changes in the current real interest rate and the future GDP deflator.

To pin everything down requires a solution for the current account. Using (5) and (6), the reaction of the long run exchange rate $(\mathrm{rf}-\mathrm{IBC})$ can be written as,

$\widehat{s}=\frac{1}{\Theta} \widehat{\Omega}+\underbrace{\left(1-\frac{1}{\Theta}\right)(1-\beta)^{2}}_{\text {as } \lambda \text { and } \epsilon \neq 1} \widehat{i}_{0}+\underbrace{\frac{\rho-1}{\Theta \rho}(1-\beta)^{2}}_{\text {as } \rho \neq 1} \widehat{r}_{0}-\underbrace{\frac{1}{\Theta} \beta(1+n)(1-\lambda)}_{\text {as } \lambda \neq 1} \widehat{P}_{h}$

as $\sum_{t=1}^{\infty} \beta^{t}=\beta /(1-\beta)$. This reduced form expression for the long run exchange rate also makes clear that the interaction between the liquidity affect and NFAs when $\rho$ and $\lambda \neq 1$ is also partly determined by the interaction of the real interest rate and the future GDP deflator,

9 In the closed economy, we can solve for output immediately; $\widehat{y}_{0}=\{[\epsilon+\beta(1-\epsilon)] / \rho\} \widehat{M}$. This condition also pins down the monetary dynamics of the economy. Consider the non-linear expression that makes $i_{t}$ a function of the endogenous variables $i_{t+1}$ and $r_{t}$. Since the nominal interest rate is non-predetermined, the expression needs to be unstable in it's forward dynamics and satisfy a saddle path property, where $r_{t}$ can be treated as an exogenous forcing variable. Since $1+r_{t}=1 / \beta$ for $t \geq 1$, when money growth is constant at $\mu_{t}=\mu$, this property implies $1+i_{t}=1 / \beta \mu$ for $t \geq 1$. To obtain $i_{0}$, I solve recursively, where the regime for money growth is such that $\mu_{t}=\mu$ for $t \geq 1$ but $\mu_{0}$ may differ from $\mu$ so the complete time path is described by $\left(\mu_{0}, \mu\right)$. This is linearized around the ZISS. 
consistent with the presence of a liquidity effect, which only arises when $\epsilon \neq 1$. Finally, (7) and (8) pin down the reaction of output and the GDP deflator in the long and short-run.

The rf-IBC and rf-UIP hold in all cases, but there is a natural benchmark when there are neither exchange rate nor current account dynamics. When $\lambda=1$, then $\Theta=1$; when $\epsilon=1$, then $\widehat{s}_{0}=\widehat{s}$; and when $\rho$, then $\widehat{\Omega}_{0}=\widehat{\Omega}$. For this specification, there is a very simple solution for the exchange rate because agents do not accumulate NFAs, and the nominal interest rate does not change when there are monetary shocks. In this case, the reaction of the exchange rate is proportional to the shock, as it would be if wages were flexible. Money is neutral in the long run, and in the short run, the change in output is also proportional to the shock. The intuition for this result is the following. As the exchange rate depreciates, the terms of trade improve, and consumers switch expenditure away from foreign goods to domestic goods. ${ }^{10}$ The real interest rate falls, and consumers want to shift expenditure into current consumption (overall). Consistent with an increase in demand, output rises. However, when $\lambda=\rho=1$, the increase in output, change in consumption, and improvement in the terms of trade net out, and there is no change in the NFA position of the economy. Because there is no change in the NFA position, the real effect of the shock lasts only until wages are revised. Finally, the nominal interest rate is unchanged due to a separation between the real side of the economy and the monetary side. ${ }^{11}$

\section{Analysis}

The analysis of the economy is based around the two channels that alter the reaction of the exchange rate to shocks, captured by rf-UIP and rf-IBC. The NFA channel relies on rf-IBC because, absent the liquidity effect, $\widehat{s}_{0}=\widehat{s}$. In analyzing the rf-IBC, I assume agents are either relatively responsive or unresponsive to endogenous changes in the terms of trade or real interest rate that result from the shock. The liquidity effect relies on $\mathrm{rf}$-UIP because, absent asset accumulation, the rf-IBC links the period exchange rate to period consumption levels. In the most general case, the two channels interact, and the rf-IBC and rf-UIP are both used.

\footnotetext{
${ }^{10}$ The terms of trade are $\widehat{P}_{f, t}-\widehat{P}_{h, t}$, where $\widehat{P}_{h, t}=\widehat{s}+\widehat{P}_{h, t}^{*}$. Since the wage is rigid, and given preference assumptions, $\widehat{P}_{h, 0}=0$. Symetrically, $\widehat{P}_{f, 0}^{*}=0$. Thus, $\widehat{s}_{0}>0$ must improve proportionally with the terms of trade. Likewise, the real exchange rate is $\widehat{q}_{0}=n \widehat{s}_{0}$.

${ }^{11}$ This is the Corsetti and Pesenti (2001) result, except that, in their analysis, the intertemporal elasticity of substitution in consumption and the interest elasticity of money demand are irrelevant for the behavior of the current account and exchange rate. That is because, as a result of PPP, the domestic real interest rate is pinned to the foreign interest rate. The result here is more comparable to Gali and Monacelli (2005), expcept they use an interest rate rule to characterize monetary policy.
} 


\subsection{Asset Accumulation and the Liquidity Effect}

An expansion in the money supply improves the terms of trade and lowers the real interest rate. Since the terms of trade and real interest rate impact consumption choices, the effects of monetary policy on the extent of borrowing or saving internationally depends on the inter and intratemporal elasticities of substitution of consumption. Any change in NFAs are reflected in the initial response of the nominal exchange rate to the shock. Taking rf-IBC, allowing $\lambda$ to vary and fixing $\rho=1$, requires us to account for changes in the GDP deflator, which reflects expenditure switching. Allowing $\rho$ to vary whilst fixing $\lambda=1$ requires us to account for changes in the real interest rate, which determines the change in the overall level of consumption, or expenditure shifting. Both possibilities are relatively straightforward to analyze because when the liquidity effect is absent, in either case, the relationship between the GDP deflator and the real interest rate is unaffected by the generalization, versus the benchmark case; that is, $\widehat{r}_{0}=-[n /(1-\beta)] \widehat{P}_{h}$ and $\widehat{P}_{h}=\widehat{M}$. Nominal consumption is eliminated from the rf-IBC using money demand. Allowing for both generalizations, we can derive the following expression for the exchange rate. ${ }^{12}$

$\widehat{s}_{0}=\widehat{s}=\frac{1-\beta[n(1-\rho)+\rho(1+n)(1-\lambda)]}{\rho \Theta+(1-\rho)(1-n)} \widehat{M}$

The strength of expenditure switching is determined through $\lambda$, so I start out by assuming $\rho=1$. The magnitude of the domestic currency depreciation falls with $\lambda$, and if the expenditure switching effect is relatively strong $(\lambda>1)$, the rise in the exchange rate is proportionally less than the shock. This result comes about through compositional changes in consumption associated with specialized outputs. ${ }^{13}$ If $\rho=\lambda=1, \widehat{C}_{h, 0}=\widehat{M}$ and $\widehat{C}_{f, 0}=0$. However, when $\lambda>1, \widehat{C}_{h, 0}>\widehat{M}$ and $\widehat{C}_{f, 0}<0$; that is, there is a relatively large boost to domestic consumption of the domestic good, and domestic agents demand less of the foreign good. Domestic exports also rise, and the economy runs a trade surplus. In the long run, this initial surplus is matched by an accumulation of NFAs, consumption (overall) remains above it's pre-shock level, but output falls below it's preshock level. This is possible because the accumulation of NFAs generates wealth for domestic agents, so they are less willing to supply labor (labor is no longer demand constrained once wages are revised), but still able to enjoy a higher level of consumption. Thus a wealth effect on labor supply creates a dampening effect on the exchange rate. Finally, the more open the economy, the greater the dampening effect, because the accumulation of NFAs required to cover the initial

\footnotetext{
${ }^{12}$ This expression is simplified significantly by the assumption that labor enters linearly into utility. However, this assumption has little impact on the main results.

${ }^{13}$ The following relies on: $\widehat{C}_{h, 0}=\widehat{C}_{0}+\lambda(1-n) \widehat{s}_{0}, \widehat{C}_{f, 0}=\widehat{C}_{0}-\lambda n \widehat{s}_{0}$ (imports), and $\widehat{C}_{h, 0}^{*}=\lambda \widehat{s}_{0}$ (exports).
} 
trade surplus is larger. As $\lambda>1$ empirically, $\mathrm{CHB}$ acts to dampen the reaction of the exchange rate to monetary shocks, and provides a potentially substantial boost to the short run effects of monetary policy, versus the closed economy.

The effects of expenditure shifting are easiest to understand when $\lambda=1$ and $\rho \neq 1$. In this case, the response of the exchange rate falls with $\rho$, and if the expenditure shifting effect is weak $(\rho>1)$, the rise in the exchange rate is also proportionally less than the shock. ${ }^{14}$ The basic mechanism is as before. The exchange rate rises, imports fall, exports rise, and domestic agents consume more of the domestic good (but now, $0<\widehat{C}_{h, 0}<\widehat{M}$ ). Households are relatively unwilling to substitute overall consumption across time, and consumption and output rise by less than the magnitude of the shock. However, as output responds to the change in the exchange rate, it reacts by more than it does in the closed economy, and there is a trade surplus. In the long run, agents accumulate NFAs, and there is a wealth effect which again explains the initial dampened response of the exchange rate to the shock. Because nominal rigidities dampen the response of the exchange rate to monetary shocks, and output is more responsive to monetary shocks than in the closed economy, superficially, the results are the same as expenditure switching case. However, important differences arise due to the change in the composition of domestic consumption and because the reaction of output is significantly less that in the expenditure switching case.

Money shocks generate genuine exchange rate dynamics when money demand is not unit interest elastic, because only then is there a liquidity effect. Despite the liquidity effect, rf-IBC is unaffected when preferences are Cobb-Douglas, and overall consumption is logarithmic (i.e., $\lambda=\rho=1)$ and, in this case, the relationship between period consumption and the exchange rate is proportional; $\widehat{s}_{0}-\widehat{\Omega}_{0}$ and $\widehat{s}-\widehat{\Omega}$. Using money demand, $\widehat{s}=\widehat{M}$. Using rf-UIP, we can solve immediately for the short run exchange rate.

$\widehat{s}_{0}=\widehat{s}+\frac{\varpi}{1-\varpi} \widehat{M}$

The parameter $\varpi<1$ drives the results in this case, and because the long run change in the exchange rate is proportional to the shock, gauging the extent of the initial reaction of the exchange rate only requires us to compare that reaction to the magnitude of the shock itself. ${ }^{15}$

\footnotetext{
${ }^{14}$ Allowing $\rho \neq 1$ also changes the income elasticity of money demand. A second feature is that, unlike the expenditure switching case, $\rho$ can vary over it's entire range. In particular, $\lim _{\rho \rightarrow \infty} \widehat{s} \rightarrow \beta<1$ and $\lim _{\rho \rightarrow 0} \widehat{s} \rightarrow \frac{1-n \beta}{1-n}>$ 1.

${ }^{15}$ We also have, $\lim _{\epsilon \rightarrow 0} \varpi \rightarrow-n(1-\beta) / \beta$ and $\lim _{\epsilon \rightarrow \infty} \varpi \rightarrow n$.
} 
Exchange rate 'overshooting' occurs if money demand is relatively interest elastic $(\epsilon>1)$, and the extent of the under (that is, when $\epsilon \in(0,1)$ ) or over reaction reduces as the economy become more open. Despite the reaction of the exchange rate, there is no long run accumulation of NFAs. However, output does not react as it would in the closed economy and, in general, none of the equivalent closed economy results go through. This is a direct result of the liquidity effect; $\widehat{i}_{0}=(\varpi / n) \widehat{r}_{0}$, where $\widehat{r}_{0}<0$ is itself also dependent on $\varpi$. The reaction of output may be greater or less than the equivalent closed economy, depending on the sign of $\varpi$. $^{16}$ Only if $\varpi \in(0,1)$ does output change by more than in the closed economy, but this only occurs when $\epsilon>1$, consistent with the exchange rate overreacting. Finally, despite the liquidity effect, without asset accumulation, the change in output exactly matches the short run change in the exchange rate.

\subsection{Exchange Rate and Output Reactions to Monetary Shocks}

$\mathrm{CHB}$ can generate short run exchange rate movements in excess of the monetary shock and the long run exchange rate. This is more pronounced the more interest elastic is money demand. However, absent any other mechanism in the economy, changes in the NFA position are also needed to dislodge the output response from that of the exchange rate; that is, the liquidity effect and asset accumulation need to interact through rf-IBC and rf-UIP. ${ }^{17}$ A good benchmark, in this case, is to be able to generate a sufficient amount of short run exchange rate variability, a short run trade surplus, and an output reaction that is less than that of the short run exchange rate. It is clear that generating a trade surplus through strong expenditure switching $(\lambda>1)$ is not the way to solve output/exchange rate problem because it adds to the reaction of output significantly. The key point is to free-up the interest and consumption elasticities of money demand. In the simpler case, the parameter $\epsilon$ determines both these elasticities of substitution. Since the consumption elasticity is typically assumed to be around one, assuming $\epsilon>1$ is problematic. However, when the consumption elasticity is captured by $\rho / \epsilon, \epsilon>1$ is fine as $\rho>1$ is also empirically more reasonable. The assumption that $\rho>1$ also produces a trade surplus when $\epsilon=1$.

\footnotetext{
${ }^{16}$ Output's response to monetary shocks is independent of openness when $\epsilon=1$, increasing in openness when $\epsilon>1$, and decreasing in openness when $\epsilon \in(0,1)$. In the long run, money is neutral.

${ }^{17}$ Adding some type of backward looking element to the model, such as Taylor style wage contracts or habit persistence, would also constrain the output reaction. Doing this would come at the cost of the simple solution derived here. Matching the data quantitatively may also require capital accumulation (with adjustment costs), as Chari et al. (2002), and other mechanisms.
} 
Once the two mechanisms interact, the analytics of the model become cumbersome, despite the simplification of the linear disutility of labor. It is possible to derive all the expressions explicitly, but to gauge the results of the more general specification I perform a very simple calibration exercise and compute three statistics of interest that capture the essential point. They are the short run reaction of the exchange rate versus the shock $\left(\widehat{s}_{0} / \widehat{M}\right)$, the reaction of the short run versus the long run exchange rate $\left(\widehat{s}_{0} / \widehat{s}\right)$, and the reaction of the short run exchange rate versus short run output $\left(\widehat{s}_{0} / \widehat{y}_{0}\right)$. It seems reasonable to expect all of these values to be greater than one. ${ }^{18}$ In terms of parameter values, empirical estimates put the consumption elasticity of money demand at or below 1 (Mankiw and Summers, 1986), which suggests setting $\rho / \epsilon \leq 1$. The interest elasticity of money demand is estimated to be anywhere between 3 and 20 (Ball, 2001), which then restricts the elasticity of the intertemporal substitution of consumption to be within a reasonable range. Typical estimates for the intratemporal elasticity of substitution are around 2; with Backus et al. (1992) using 1.5. ${ }^{19}$ Finally, the discount rate is set at $\beta=0.96$, and openness at $n=0.5$ in all cases.

\section{Table One Here}

The main points made in the previous section all hold here. Asset accumulation dampens the response of the exchange rate relative to the benchmark case, the liquidity effect produces an over or under reaction in the short run exchange rate, asset accumulation does little to dampen the liquidity effect (likewise, the liquidity effect has little impact on the extent of asset accumulation), and finally, asset accumulation matters for the reaction of output, but when $\lambda>1$, the output reaction is far greater than the exchange rate reaction. The case in which the intertemporal elasticity of consumption differs from one is most promising. When $\rho>1$ the consumption elasticity of money demand is nearer unity, when $\epsilon>1$. Although expenditure switching is still

\footnotetext{
${ }^{18}$ There are two comments worth making regarding this approach. First, given the simplicity of the model, the statistics only act as a guide to the relative strength of each effect. Second, it is possible to perform a more 'quantitative' analysis, without a full simulation. For example, Betts and Devereux (2000) generate a random sample of monetary shocks and use their deterministic model to compute implied moments for the exchange rate and other endogenous variables (in first differences). Since certainty equivalence applies, the equations of the stochastic version of the model are the same. It is straightforward to do that type of analysis here.

${ }^{19}$ Naturally, these studies apply parameter estimates, or estimate parameters of interest, independently from one another. Bergin $(2003,2006)$ estimates a number of these parameters jointly, in an open economy macro model, featuring many of the frictions that are needed to help such a framework match the data. For example, his estimate of the intratemporal elasticity of substitution in consumption is slightly above 1 , whereas some micro estimates put this value at nearer 5 .
} 
present, it's role is mitigated by the effect of expenditure shifting, which is strengthened when $\rho>1$. In the parameterized example, we can see that the exchange rate/output statistic is above one, indicating that the exchange rate reacts by more than output, the exchange rate overreacts on impact, and there is also an accumulation of NFAs in the long run, which is not shown explicitly, but which is consistent with the long run reaction of the exchange rate being less than proportional to the shock.

This analysis does not aim to match the data, rather, investigate the implications of $\mathrm{CHB}$ for exchange rate behavior. Combined with sticky wages, $\mathrm{CHB}$ allows monetary shocks to generate exchange rate fluctuations, but $\mathrm{CHB}$ also requires specialized outputs. That itself gives rise to an expenditure switching effect which, even for a relatively conservative $\lambda$ 's, produces a very strong reaction from output to monetary shocks. To be broadly consistent with empirical estimates, we ideally want $\lambda$ and $\rho$ to both be greater than one. There are two obvious candidate solutions to restraining the output response, independent of $\rho$. One is related to incorporating a more complex set of dynamics into the economy, and performing a quantitative analysis of the impact of $\mathrm{CHB}$, which is not the focus of this paper. ${ }^{20}$ The other is associated with different ways of breaking the assumption of purchasing power parity. Theoretically, deviations from purchasing power parity arise from three sources: multiple traded goods and different consumption baskets differ across countries (CHB), deviations in the law of one price for traded goods across countries, and movements in the relative price of non traded to traded goods across countries.

The introduction of non traded goods production or monopolistically competitive firms that can segment the market for their specialized product internationally (PTM) both violate the law of one price. All else equal, the introduction of non traded goods and PTM both mitigate the output effects of monetary shocks because they change the role played by the terms of trade. When there are non traded goods, and the traded good is homogenous, with it's price given by world markets, consumption of both goods rises when there is an unanticipated increase in the money supply. But the rise in output is not as large as with specialized outputs because

\footnotetext{
${ }^{20}$ Backward looking elements, would imply that output, at least initially, react by less. However, the liquidity effect relies on that fact that the real interest rate changes, and if this changes by less, then the liquidity effect will be diminished. Thus, adding a backward looking element to the model would reduce the reaction of output, but also potentially reduce the degree of over reaction in the exchange rate. There is also a secondary effect from such a setting; the transition to the steady state does not occur after one period. Because the accumulation of NFAs is slower, this changes, albeit marginally, the initial reaction of the exchange rate, via the wealth effects on labor supply.
} 
production is only linked to the non traded good. When there is PTM, even though the economy produces a specialized output, when the exchange rate rises, not all of the effects feed through to output, and in the most extreme case, the expenditure switching effect of monetary policy can be reduced to zero. Initially therefore, it seems that breaking the law of one price is important, in that it adds to the variability of the exchange rate. However, in most models it plays a second role (over and above the inclusion of other more complicated features) versus the $\mathrm{CHB}$ case, because it does not require such a high an intertemporal elasticity of substitution in consumption to combat the large effects of expenditure switching. Papers that attempt to determine the importance of expenditure switching quantitatively therefore need to carefully judge the role played by the intertemporal elasticity of substitution, and by implication, the income elasticity of money demand. In this sense, it matters how fluctuations in the exchange rate are generated.

\section{Conclusion}

Monetary shocks produce exchange rate fluctuations when there is $\mathrm{CHB}$. That is despite the law of one price holding. However, output is far more sensitive to the parameter that governs the expenditure switching effects of exchange rate movements when there is $\mathrm{CHB}$. This places a stronger emphasis on the expenditure shifting effects of monetary shocks to mitigate the output response. This type of expenditure shifting is also consistent with reducing the income elasticity of money demand, whilst maintaining a relatively elastic response of money demand to changes in the nominal interest rate, as emphasized in previous studies. 


\section{References}

Backus, D., Kehoe, P., and Kydland, F., 1994. International Real Business Cycles, Journal of Political Economy 100, 745-775.

Ball, L., 2001. Another Look at Long Run Money Demand, Journal of Monetary Economics 47, 31-44.

Bergin, P., 2003. Putting the New Open Economy Macroeconomics to a Test, Journal of International Economics 60, 3-34.

Bergin, P., 2006. How Well Can the New Open Economy Macroeconomics Explain the Exchange Rate and Current Account, Journal of International Money and Finance 25, 675-701.

Betts, C., Devereux, M., 2000. Exchange Rate Dynamics in a Model of Pricing to Market, Journal of International Economics 50, 214-244.

Chari, V, Kehoe, P, McGratten, E., 2002. Can Sticky Price Models Generate Volatile and Persistent Real Exchange Rates?, Review of Economic Studies 69, 533-564.

Corsetti, G., Pesenti, P., 2001. Welfare and Macroeconomic Interdependence, Quarterly Journal of Economics 116, 421-446.

Devereux, M., Engel, C., 2003. Monetary Policy in the Open Economy Revisited: Exchange Rate Flexibility and Price Setting Behavior, Review of Economic Studies 70, 765-783.

Duarte, M., Obstfeld, M., 2007. Monetary Policy in the Open Economy Revisited: The Case for Exchange-Rate Flexibility Restored, Journal of International Money and Finance, forthcoming.

Eichenbaum, M., Evans, C., 1995. Some Empirical Evidence on the Effects of Shocks to Monetary Policy on Exchange Rates, Quarterly Journal of Economics 110, 975-1009.

Faia, E., Monacelli, T., 2006. Optimal Monetary Policy in A Small Open Economy with Home Bias, Journal of Money, Credit and Banking, forthcoming.

Faust, J., and Rogers, J., 2003. Monetary Policy's Role in Exchange Rate Behavior, Journal of Monetary Economics 50, 1403-1424.

Gali, J., Monacelli, T., 2005. Optimal Monetary Policy and Exchange Rate Volatility in a Small Open Economy, Review of Economic Studies 72, 707-734.

Hansen, G., 1985. Indivisible Labor and the Business Cycle, Journal of Monetary Economics 16, 309-327. 
Hau, H., 2002. Real Exchange Rate Volatility and Economic Openness: Theory and Evidence, Journal of Money, Credit and Banking 34, 611-630.

Jung, K., 2007. Can the New Open Economy Macroeconomic Model Explain Exchange Rate Fluctuations?, Journal of International Economics 72, 381-408.

Kollmann, R., 2001. The Exchange Rate in a Dynamic Optimizing Business Cycle Model with Nominal Rigidities: A Quantitative Investigation, Journal of International Economics 55, 243-262.

Kollmann, R., 2006. International Portfolio Equilibrium and the Current Account, CEPR DP 3819.

Lane, P., 2001. Money Shocks and the Current Account, in Money, Factor Mobility and Trade: Essays in Honour of Robert Mundell, Calvo, G., Dornbusch, R., Obstfeld, M. (eds.), MIT Press. Mankiw, G., Summers, L., 1986. Money Demand and the Effects of Fiscal Policies, Journal of Money, Credit and Banking 18, 415-429.

Monacelli, T., 2004. Into the Mussa Puzzle: Monetary Policy Regimes and the Real Exchange Rate in a Small Open Economy, Journal of International Economics 62, 191-217.

Obstfeld, M., Rogoff, K., 1995. Exchange Rate Dynamics Redux, Journal of Political Economy $103,624-660$.

Tesar, L., and Gorodnichenko, Y., 2007. Border Effect or Country Effect: Seattle is 110 Miles from Vancouver After All, mimeo, University of Michigan, Ann Arbor.

Tille, C., 2001. The Role of Consumption Substitutability in the International Transmission of Monetary Shocks, Journal of International Economics 53, 421-444.

Warnock, F., 2003. Exchange Rate Dynamics and The Welfare Effects of Monetary Policy in a Two Country Model with Home Product Bias, Journal of International Money and Finance 22, 343-363.

Zettelmeyer, J., 2004. The Impact of Monetary Policy on the Exchange Rate: Evidence From Three Small Open Economies, Journal of Monetary Economics 51, 635-652. 


\section{Appendix}

Firms choose between differentiated labor types and produce a single good. They maximize profits, $P_{h, t} y_{t}-\int_{0}^{1} w_{t}(j) l_{t}(j) d j$, subject to their production function, implying $l_{t}(j)=$ $\left(w_{t}(j) / w_{t}\right)^{-\sigma} y_{t}^{\alpha}$, where $w_{t}=\left(\int_{0}^{1} w_{t}(j)^{1-\sigma} d j\right)^{1 /(1-\sigma)}$ is the wage index. All households set the same wage in equilibrium, $w_{t}=w_{t}(j) \forall j$, with labor demand given by,

$y_{h, t}=\left(\alpha w_{t} / P_{h, t}\right)^{1 /(1-\alpha)}$

The budget constraint for domestic household $j$ is,

$B_{t}-B_{t-1}\left(1+i_{t-1}\right) \geq P_{h, t} y_{t}-P_{t} C_{t}-T_{t}+M_{t-1}-M_{t}$

Given the preference assumptions, we have the following optimality conditions,

$P_{t+1} C_{t+1}^{\rho}=P_{t} C_{t}^{\rho} \beta\left(1+i_{t}\right)$

$M_{t} / P_{t}=C_{t}^{\rho / \epsilon}\left[a\left(\frac{1+i_{t}}{i_{t}}\right)\right]^{1 / \epsilon}$

$w_{t}=[\kappa \sigma /(\sigma-1)] \mathbb{E}_{t-1}\left\{P_{t} C_{t}^{\rho}\right\}$

A similar set of conditions hold in the foreign economy. Since, $P_{t} C_{t}=P_{h, t} C_{h, t}+P_{f, t} C_{f, t}$, the domestic intratemporal conditions are,

$C_{h, t}=(1-\nu) C_{t}\left(P_{t} / P_{h, t}\right)^{\lambda}$ and $C_{f, t}=\nu C_{t}\left(P_{t} / P_{f, t}\right)^{\lambda}$

where $P_{t}=\left((1-\nu) P_{h, t}^{1-\lambda}+\nu P_{f, t}^{1-\lambda}\right)^{1 /(1-\lambda)}$. In the foreign economy,

$C_{t}^{*}=\left(\nu^{* 1 / \lambda} C_{h, t}^{*(\lambda-1) / \lambda}+\left(1-\nu^{*}\right)^{1 / \lambda} C_{f, t}^{*(\lambda-1) / \lambda}\right)^{\lambda /(\lambda-1)} ; \nu^{*}=\gamma \phi^{*}$

where a similar set of optimality conditions hold. I impose $\phi=\phi^{*}$, and home bias requires $\phi<1$.

The respective resource constraints for the domestic and foreign economies (with steady-state versions) are,

$$
\begin{aligned}
y_{t} & =y_{h, t}+y_{h, t}^{*}=C_{h, t}+\omega C_{h, t}^{*}=\left(P_{t} / P_{h, t}\right)^{\lambda}\left[(1-\nu) C_{t}+\omega \nu^{*} C_{t}^{*} q_{t}^{\lambda}\right] \\
y & =(1-\nu) C+\omega \nu^{*} C^{*} \\
y_{t}^{*} & =y_{f, t}+y_{f, t}^{*}=\frac{1}{\omega} C_{f, t}+C_{f, t}^{*}=\left(P_{t} / P_{f, t}\right)^{\lambda}\left[\frac{\nu}{\omega} C_{t}+\left(1-\nu^{*}\right) C_{t}^{*} q_{t}^{\lambda}\right] \\
y^{*} & =\frac{\nu}{\omega} C+\left(1-\nu^{*}\right) C^{*}
\end{aligned}
$$


The small open economy approximation applies $\omega \rightarrow \infty$. In that case, $\gamma \rightarrow 0, \nu^{*} \rightarrow 0, \nu \rightarrow \phi$. Also, $\omega \nu^{*}=\omega \phi \gamma=[(1-\gamma) / \gamma] \phi \gamma=(1-\gamma) \phi=\phi$. The previous expressions become,

$$
\begin{aligned}
y_{t} & =\left(P_{t} / P_{h, t}\right)^{\lambda}\left[(1-\phi) C_{t}+\phi C_{t}^{*} q_{t}^{\lambda}\right] \text { and } y=(1-\phi) C+\phi C^{*} \\
y_{t}^{*} & =C_{t}^{*} \text { and } y^{*}=C^{*}
\end{aligned}
$$

The steady state is one with balanced trade. This implies $C=C^{*}$, where $C^{*}$ is a per capita measure and $C$ is an aggregate and per capita measure, and $y=C$, so that the resource constraint, $C=C_{h}+\omega C_{h}^{*}, C_{h} / y=(1-\phi)$ and $\omega C_{h}^{*} / y=\phi$. In the text I define $n \equiv 1-\phi$.

In the closed economy, $n=1(\phi=0), P_{t}=P_{h, t}$, and so, $y_{t}=C_{t}=\chi^{\rho}$, for $t \geq 1$. To understand the transmission of money shocks note, $\widehat{w}_{0}=\widehat{P}_{0}=0$. Short run money demand gives an ' $L M$ curve'; $\widehat{y}_{0}=\left(\epsilon \widehat{M}+\widehat{\beta i_{0}}\right) / \rho$. Long run money demand pins down the future price level because, at date $t=0, \widehat{M}_{t}$ jumps permanently and unexpectedly from zero to $\widehat{M}>0$, so that, $\widehat{P}=\widehat{M}$. The Euler equation, then gives use the 'IS curve'; $\widehat{y}_{0}=\left[\widehat{M}-(1-\beta) \widehat{i_{0}}\right] / \rho$. Solving for aggregate demand,

$\widehat{y}_{0}=\left[\frac{\epsilon+\beta(1-\epsilon)}{\rho}\right] \widehat{M}$

Now we see that, if $\epsilon=1, \widehat{y}_{0}=\frac{1}{\rho} \widehat{M}$. Alternatively, suppose $\rho=1$, then, if $\epsilon>1, \widehat{y}_{0}>\widehat{M}$. To understand the mechanism we need only describe the behavior of the real and nominal interest rates. From the IS and LM conditions, $\widehat{i}_{0}=(1-\epsilon) \widehat{M}$. From the real Euler equation, $\widehat{r}_{0}=-\frac{\rho}{1-\beta} \widehat{y}_{0}=-\left[\frac{\epsilon+\beta(1-\epsilon)}{1-\beta}\right] \widehat{M}$. These conditions produce, $\widehat{i}_{0}=\frac{(1-\beta)(\epsilon-1)}{1+(1-\beta)(\epsilon-1)} \widehat{r}_{0}$, given in the main text. It is immediate that $\rho$ does not matter for the behavior of the interest rates. For any $\epsilon, \widehat{r}_{0}<0$. However, for $\epsilon>1, \widehat{i}_{0}<0$ and $\epsilon<1, \widehat{i}_{0}>0$. This explains why $\widehat{y}_{0}>\widehat{M}$ when $\epsilon>1$. 
Table One

\begin{tabular}{llllll}
\hline \multicolumn{3}{c}{ Elasticities } & \multicolumn{3}{l}{ Endogenous Variables } \\
\hline \hline$\lambda$ & $\rho$ & $\epsilon$ & $\widehat{s}_{0} / \widehat{M}$ & $\widehat{s}_{0} / \widehat{s}$ & $\widehat{s}_{0} / \widehat{y}_{0}$ \\
\hline 1 & 1 & 1 & 1 & 1 & 1 \\
1.5 & 1 & 1 & 0.98 & 1 & 0.72 \\
1 & 3 & 1 & 0.98 & 1 & 1.20 \\
1 & 1 & 4 & 1.06 & 1.06 & 1 \\
1.5 & 1 & 4 & 1.05 & 1.06 & 0.72 \\
1 & 3 & 4 & 1.04 & 1.06 & 1.19 \\
\hline \hline
\end{tabular}

